\title{
A DECISION SUPPORT SYSTEM FOR SPACE CONFLICT RESOLUTION IN BUILDING CONSTRUCTION
}

\author{
Sy-Jye Guo* and Chun-Ta Wu** \\ * Associate professor, Dept. of Civil Engineering, National Taiwan University \\ ** Graduate student, Dept. of Civil Engineering, National Taiwan University
}

\begin{abstract}
Numerous workers, equipment, material, temporary facilities and permanent structures share or interfere with the limited space during the construction period. The site layout and space planning has been a significant and complex problem for construction engineers. This research established a set of procedure and criteria for identifying and resolving space conflicts. A computer-based decision support system (DSS) which combined the criteria and heuristic rules was developed to solve this significant and complex problem more efficiently and precisely.
\end{abstract}

Keywords: Space, planning, conflict, resolution, DSS

\section{INTRODUCTION}

Building construction involves various trades of subcontractors working in a constrained area during the construction period. Each subcontractor require certain working space, equipment space, material storage, travel path as well as some protected area for completing his own task. It happens all the time that the crowded job site was one of the major causes of productivity decrease and schedule interference or delay. A detail site layout planning and space allocation for subcontractors can reveal the space conflicts in advance and thus improve the work flow and efficiency. Without the space management plan, the job site can turn out to be a chaotic place which filled with interfered workers, interrupted or inefficient works, schedule delays, and numerous complaints that destroy the morale.

Traditionally the site engineer needs to arrange the day-to-day activities on the job site according to the planned schedule. However, this type of arrangement requires space allocation to various trades of workers during different time frames. Space conflicts occurs frequently on may job sites because the lack of a formal procedures or methodology to identify all the potential space conflicts. Even an experienced project manager may not be able to identify all the conflicts. When serious space conflicts occur, the schedule is often thus delayed. This is the key point that if a decision support system can be developed to help the manager identify the space conflicts and make suggestions to solve them beforehand, then the productivity can be essentially improved on the job site.

\section{LITERATURE REVIEWS}

Space management involves three aspects of research: site layout planning, path planning and space scheduling. Site layout planning mainly deals with the layout of temporary facilities on the job site. Many researchers present various approaches for locating the most appropriate layout of temporary facilities (Tommelein, 1993, Yeh, 1995, Cheng, 1996, Li, 1998, Hegazy, 1999, Zouein,1999). Geographic Information System(GIS), Artificial Intelligence(AI), and Genetic Algorithm(GA) have been utilized by previous studies to decide the best layout according to the shortest travel distance or minimum travel cost between the temporary facilities. However, it is argued that a minimum travelling distance or cost can only apply to an optimization of transportation, not directly to the optimization of the work itself, nor a shortest working period. Previous site layout studies did not pay enough attention to this argument. Another argument is that most of these studies did not consider the impact of time on the space availability. For example, the job site office can be moved into the building itself when the structure is partially completed and release space for other utilization. The time frame impact are more often neglected or over-simplified in most of these previous studies.

Space management involves three aspects of research: site layout planning, path planning and space scheduling. Site layout planning mainly deals with the layout of temporary facilities on the job site. Many researchers present various approaches for locating the most appropriate layout of temporary facilities (Tommelein, 1993, Yeh, 1995, Cheng, 1996, Li, 1998, Hegazy, 1999, Zouein,1999). Geographic Information System(GIS), Artificial 
Intelligence(AI), and Genetic Algorithm(GA) have been utilized by previous studies to decide the best layout according to the shortest travel distance or minimum travel cost between the temporary facilities. However, it is argued that a minimum travelling distance or cost can only apply to an optimization of transportation, not directly to the optimization of the work itself, nor a shortest working period. Previous site layout studies did not pay enough attention to this argument. Another argument is that most of these studies did not consider the impact of time on the space availability. For example, the job site office can be moved into the building itself when the structure is partially completed and release space for other utilization. The time frame impact are more often neglected or over-simplified in most of these previous studies.

The purpose of space scheduling is to combine all the working elements (worker, equipment, material, path, temporary facilities and physical layouts) subjected to the variations of different time frame or schedule, and thus to eliminate or minimize the space conflicts between theses working elements. This complex problem involves consideration of space as a resource which will vary subjected to time, and the space allocation procedure need to be formally and accordingly executed based on a set of requirements or constraints of various working elements. Tommelein (1993) developed MovePlan for determination of temporary facilities according to the CPM schedule. Thabet (1994) defined the work space demand and availability for high rise building construction. He also proposed the idea of space capacity factor $(\mathrm{SCF})$ to describe the productivity loss due to space constraints. A space-constrained resource-constrained scheduling system (SCaRC) was then developed in 1997. Riley (1995) defined the patterns of construction-space use in multistory building and presented space planning method regarding various patterns of use(1997). Recently, 4D space planning specification and development for construction work space are undergoing (Riley, 1998). Similar research has been also executed by Akinci (1998) for reducing non-value-adding activities due to time-space conflicts. Then timespace conflict analysis based on 4D production model was proposed (Akinci, 1998).

Although many researchers had devoted efforts to target this complex space-scheduling problem, few studies utilized a formal procedure to analyze the patterns of space conflicts and provided resolution strategies for them. Moreover, the possibility that the overlapped working space is not considered by most studies. This study would try to release those assumptions and come up with a more thorough result than previous studies have ever made.

\section{SYSTEM STRUCTURE}

This study utilized two typical tools, AutoCAD for space planning and Ms-Project for scheduling, to target the space conflict problem. Both the two software are well known to most engineers. Once the space conflict is detected, the decision support system will provide an appropriate resolution strategy to eliminate or minimize the conflict based on the decision rules generated by this study. The system structure is shown as Figure 1.

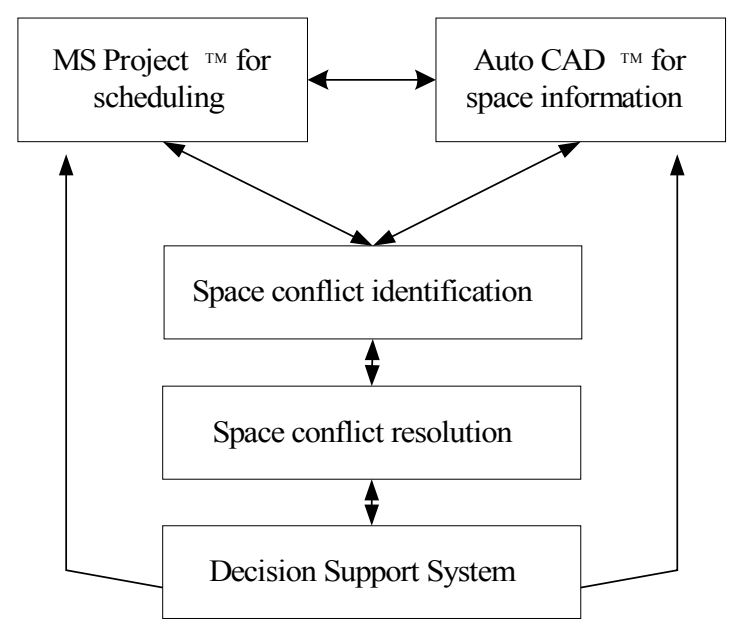

Fig. 1. System structure of space conflict resolution

\section{METHODOLOGY}

\subsection{Available space and space demand}

The available space for a building construction is divided into four categories: Exterior of job site, interior of job site, inside the structure, and space provided by temporary structures such as platforms and scaffolds. The first two groups are only for space on the ground. Available space inside the structure is then classified by different story and zone(on a same floor). The total available space data then can be compiled by the codes of different available categories which include the size of space and the period of time for availability.

The space demand is derived from the planned schedule and breakdown as a hierarchical structure as in Figure 2. For various activities, different colors are utilized for identification. For various types of space, such as working space, storage space, waste space or set-up space are then classified by different patterns of lines. The space user can be easily identified by various colors and patterns. 


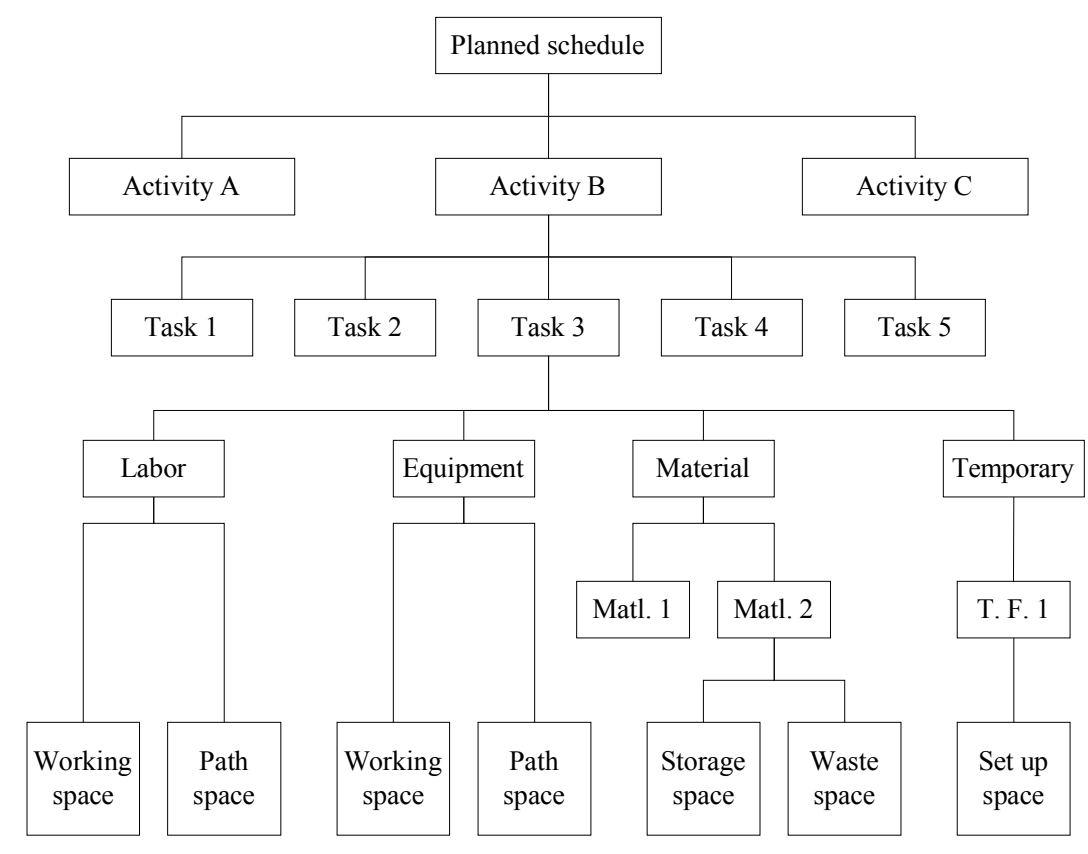

Figure 2. Hierarchical structure of space demand

\subsection{Space conflicts identification}

The space demand for various activities are specified by site engineers and displayed on the CAD drawing. Combined these space demands on the same time period will reveal the space conflicts between different activities. This idea is similar to the combination of various design drawings for identifying space conflict of final design. In the construction stage, the combination of space demand can help the engineer to identify the potential space conflicts during the construction phase. Space conflict is defined as more than one space demand is claimed on a specific available space during a same time period. All the space conflicts are then compiled.

\subsection{Resolution strategy}

To overcome the space conflicts, Three aspects of resolution strategy are considered. The first strategy is to adjust the space demand. This approach involves changing the location of space or dividing the original space demand to several smaller areas so that the space conflicts can be eliminated. This approach does not incur changes of the original schedule and if it is feasible, the impact on the construction site could be minimal. The second strategy is to adjust the planned schedule to avoid the space conflicts. Adjusting the starting time of an activity, reducing the length of time for space requirement, or splitting the time period of working are typical solutions for this strategy. This approach would usually delay the original schedule and the minimum delay is the rule for space conflict resolution. The third strategy is a hybrid approach which consider adjusting the space demand and the scheduling sequence at the same time. Changing the quantity of space users or even the construction method may become a good solution to the space conflicts.

\subsection{Criteria for resolving space conflict}

Once the strategy is set up, criteria for deciding which activity is to be modified become essential. To resolve the space conflict, the space characteristics for each activity involved in the conflict need to be analyzed. This research builds up a series of criteria for analyzing the characteristics of the conflicts and help the engineer to decide which activity needs to be adjusted:

1. Logic sequence between activities: if conflict is identified, the first thing to check is the logic sequence between these activities. If the logic sequence relation exists, the space demand for successive activities need to be adjusted.

2. Critical path: activity on the critical path has the priority to claim the space demand, other non-critical activities will be modified.

3. Space dividable or not: if the space demand can be divided into several smaller areas, then the space conflict may be eliminated.

4. Location changeable or not: if the space demand can be changed, such as the material storage, then the space conflict may be eliminated.

5. Size of space adjustable or not: if the space demand can be adjusted, i.e., constrained to a certain limit, the space conflict could be 
eliminated although the productivity of the adjusted activity may be effected.

6. Start time for occupying the conflicting space: the start time for an activity to occupy the space could be a criterion for deciding which activity to be adjusted.

7. Length of time for occupancy: the time period for occupancy could also become a criterion for deciding the conflict resolution approach.

Despite the aforementioned criteria, some other factors may also help to analyze and resolve the conflicts. These affiliate criteria include the size of conflict, location of conflict, duration of the conflict and other specific characteristic of conflict tasks. This study also defines the interference space percentage (ISP) and interference duration percentage (IDP) for further analyses and decision rules. The categories and criteria for resolving space conflicts are summarized as in Table 1.

Table 1. Criteria for resolving space conflicts

\begin{tabular}{|c|c|c|c|}
\hline \multirow{4}{*}{$\begin{array}{c}\text { Major } \\
\text { criteria }\end{array}$} & \multicolumn{2}{|c|}{ Affiliate criteria } \\
\cline { 2 - 4 } & $\begin{array}{c}\text { Logic } \\
\text { sequence }\end{array}$ & Space related & Time related \\
\cline { 2 - 4 } & Critical path & Size of conflict & $\begin{array}{c}\text { Duration of } \\
\text { conflict }\end{array}$ \\
\cline { 2 - 4 } & $\begin{array}{c}\text { Duration of } \\
\text { conflict }\end{array}$ \\
\hline \multirow{1}{*}{ dividable } & $\begin{array}{c}\text { Interference } \\
\text { space } \\
\text { percentage } \\
\text { (ISP) }\end{array}$ & $\begin{array}{c}\text { Interference } \\
\text { duration } \\
\text { percentage } \\
\text { (IDP) }\end{array}$ \\
\cline { 2 - 4 } & $\begin{array}{c}\text { Location } \\
\text { changeable }\end{array}$ & $\begin{array}{c}\text { Location of } \\
\text { conflict }\end{array}$ & $\begin{array}{c}\text { Specific } \\
\text { characteristic } \\
\text { of conflict } \\
\text { tasks }\end{array}$ \\
\cline { 2 - 4 } & $\begin{array}{c}\text { Size } \\
\text { adjustable }\end{array}$ & \multicolumn{2}{|c|}{$\begin{array}{c}\text { Other related data or } \\
\text { characteristics }\end{array}$} \\
\cline { 2 - 4 } & $\begin{array}{c}\text { Start time of } \\
\text { occupancy }\end{array}$ & \multicolumn{2}{|c|}{$\begin{array}{c}\text { Other related data or } \\
\text { characteristics }\end{array}$} \\
\cline { 2 - 4 } & $\begin{array}{c}\text { Length of } \\
\text { time for } \\
\text { occupancy }\end{array}$ & \multicolumn{2}{|c|}{$\begin{array}{c}\text { Other related data or } \\
\text { characteristics }\end{array}$} \\
\hline
\end{tabular}

\subsection{Space conflict re-identification}

Once the original conflicts are resolved, the whole process of conflict identification and resolution needs to be executed again to ensure than there is no further space conflicts occur due to the adjusted space allocation or schedule rearrangement. Usually this process can be completed in a short period. If further conflicts occur continuously or trigger even more problems, then the resolution strategy may need to be modified. In this circumstance, rearrange the space utilization or schedule may not be an effective way to solve all the conflicts. The hybrid approach, such as changing the construction method, may become more effective.

\subsection{Path demand analysis}

Even though all the space conflicts are solved, the space planning is not yet finished. The final step is to ensure that there is enough path space for all the required labors, equipment and material transportation. This study defined a minimum width of path and minimum height of path as follows:

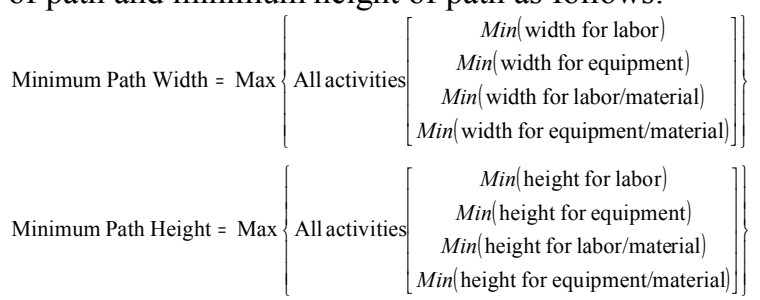

\section{CASE ILLUSTRATION}

A typical 12-story RC residential building was utilized in this research to demonstrate how the space conflicts are identified and resolved by the decision support system. The size of the job site is about $1000 \mathrm{~m}^{2}$ and the total floor area is $5775 \mathrm{~m}^{2}$. The space planning for each floor requires various space requirements for survey, reinforcing steel, plumbing and electrical, scaffold, formwork, concrete, and management of the general contractor. According to the initial schedule and space requirement from all these subcontractors, the combined CAD drawings show many space conflicts as shown in Figure 3.

To resolve the space conflicts, the decision support system will first compile all these conflicts according to the space users, type of space, duration of the conflicts, location/size of the conflicts as well as other related data of the competing activities. A list of conflicts was then established. In this case, since the floor area is very limited, adjusting the size of space requirement for subcontractors become unreasonable. A more suitable approach to solve the problem is adjusting the planned schedule to avoid the conflicts. By splitting the reinforcing steel tasks of the columns to be erected, the conflicts between the reinforcing steel and plumbing/electrical can be eliminated as shown in Figure 4. The decision support system will then examine if there is other conflicts unsolved. Although on the 2D drawing shows a dummy conflict between the scaffold and temporary toilet, there is no actual space conflict. The toilet did not interfere with the scaffold on the $7^{\text {th }}$ floor because it is on the ground level. If all the path requirements are also satisfied, the decision support system will 
then pass the information to the schedule software and update the re-arranged schedule.

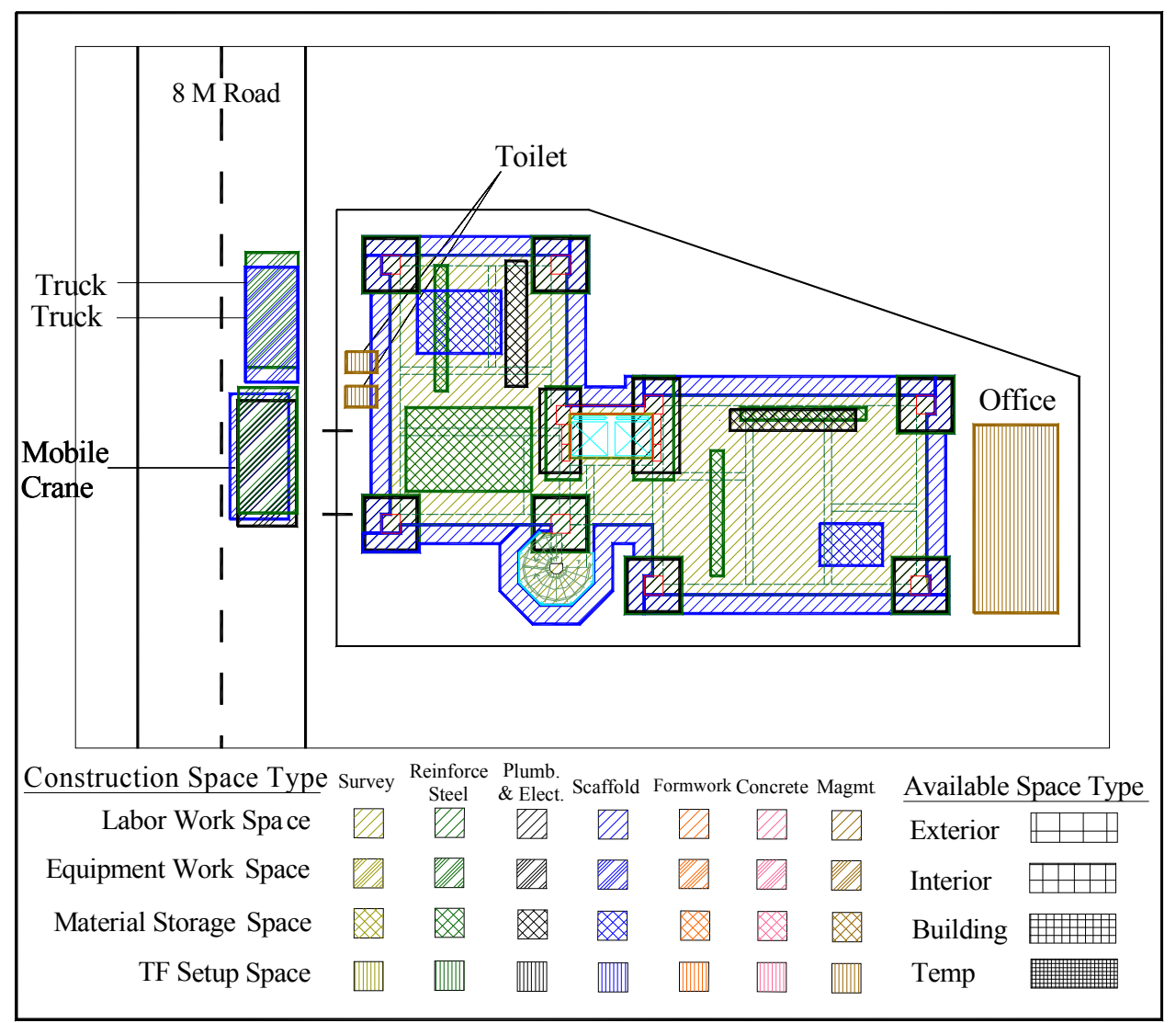

Figure 3. Conflicts identification for all subcontractors 


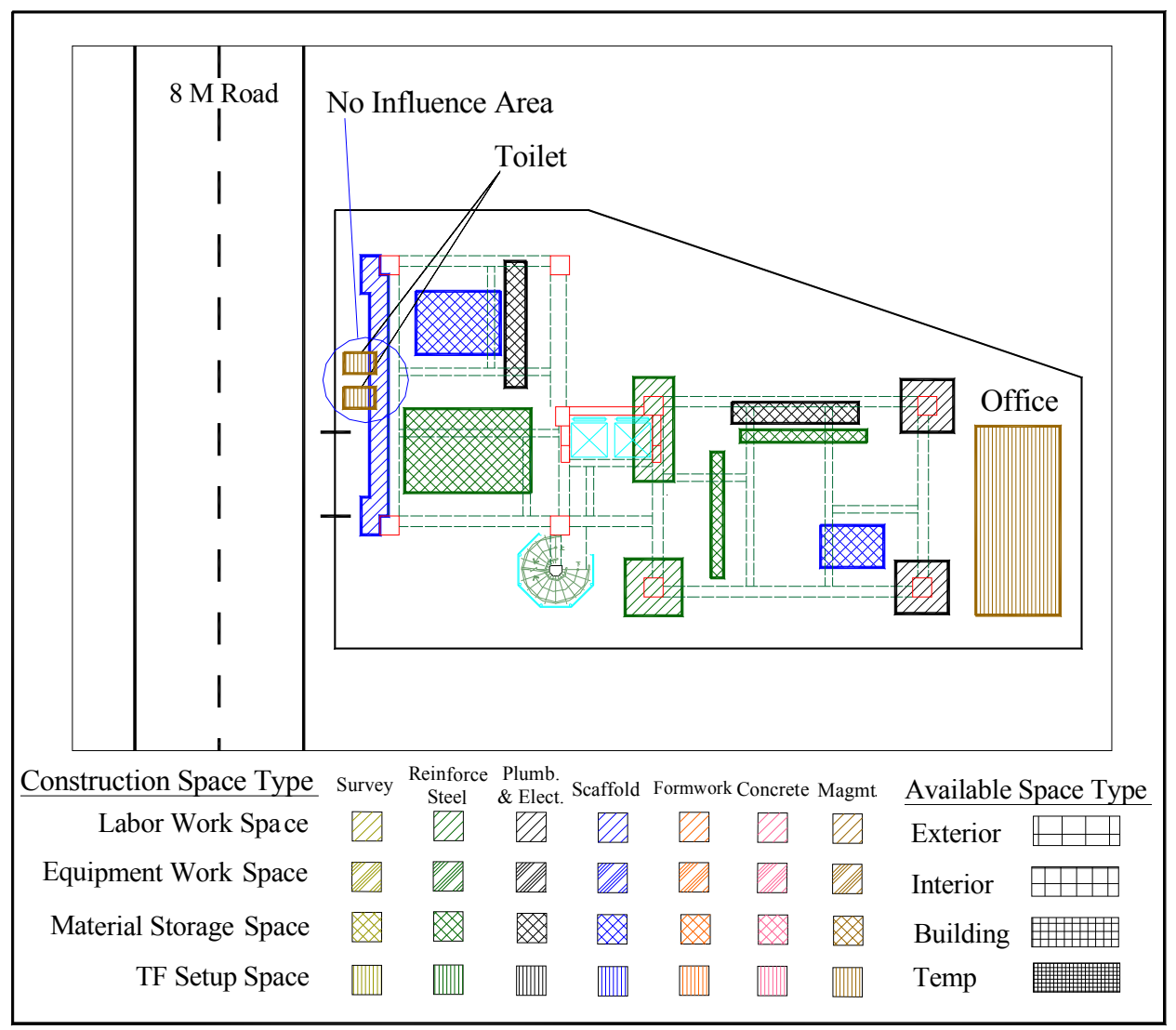

Figure 4. Conflict resolution between reinforcing steel and plumbing

\section{CONCLUSIONS}

Numerous workers, equipment, material, temporary facilities and permanent structures share or interfere with the limited space during the construction period. Since the space constraints may affect the moving path and productivity, it is essential to organize the space and layout in an efficient way that the space conflicts can be minimized. The space availability on site may change due to the time and schedule arrangement. The site layout and space planning has been a significant and complex problem for construction engineers.

The construction industry lack of an efficient and systematic approach for site layout and space planning. This research established a set of procedure and criteria for identifying and resolving space conflicts. Many researchers solve this problem based on a minimum travelling distance or cost between temporary facilities. However, a minimum travelling distance or cost can only apply to an optimization of transportation, not directly to the optimization of the work itself, nor a shortest working period. This study considered the space availability due to time and schedule, the productivity loss due to path interference and space constraints, as well as the possibility of alternative space to achieve the space conflict resolution as well as the site layout planning and optimal space utilization. Case studies and expert interviews are conducted to induce heuristic rules for comparison with the result of the developed procedure and criteria. Finally, a computer-based decision support system (DSS) which combined the criteria and heuristic rules was developed to solve this significant and complex problem more efficiently and precisely.

\section{REFERENCES}

[1] Akinci, B., Fischer, M. and Zabelle, T. "Proactive approach for reducing non-value adding activities due to time-space conflicts." Proceeding of the 6th Annual Conference on Lean Construction, Brazil, 1998.

[2] Akinci, B. and Fischer, M. "Time-space conflict analysis based on 4D production models." Proceedings of Computing in Civil Engineering, ASCE, 342-353, 1998.

[3] Choo, J.H. and Tommelein, I.D. "Space scheduling using flow analysis." Proceedings of the 7th Annual Conference on Lean Construction, USA, 299-312, 1999.

[4] Cheng, M.Y. and O'Connor, J.T. "ArcSite: Enhanced GIS for construction site layout." 
Journal of Construction Engineering and Management, ASCE, 122(4), 329-336, 1996.

[5] Hegazy, T. and Elbeltagi, E. "EvoSite: evolutionbased model for site lay- out planning." Journal of Computing in Civil Engineering, ASCE, 13(3), 198-206, 1999.

[6] Li, H., and Love, P.E.D. "Site-level facilities layout using genetic algorithms" Journal of Computing in Civil Engineering, ASCE, 12(4), 227-231, 1998.

[7] Riley, D.R. and Sanvido, V.E. "Patterns of construction-space use in multistory buildings." Journal of Construction Engineering and Management, ASCE, 121(4), 464-473, 1995.

[8] Riley, D.R. and Sanvido, V.E. "Space planning method for multistory building construction" 。 Journal of Construction Engineering and Management, ASCE, 123(2), 464-473, 1997.

[9] Riley, D.R. "4D space planning specification development for construction work spaces." Proceedings of Computing In Civil Engineering, ASCE, 342-353, 1998.

[10] Thabet, W.Y. and Beliveau, Y.J. "Modeling work space to schedule re- petitive floors in multistory buildings." Journal of Construction Engineering and Management, ASCE, 120(4), 96-116, 1994.

[11] Thabet, W.Y. and Beliveau, Y.J. "SCaRC: Space-constrained resource- constrained scheduling system." Journal of Computing in Civil Engineering, ASCE, 11(1), 48-59, 1997.

[12] Tommelein, I.D., Levitt, R.E., Hayes-Roth, B., and Confrey, T. "Sight-Plan experiments: alternative strategies for site layout design." Journal of Computing in Civil Engineering, ASCE, 5(1), 42-63, 1991.

[13] Tommelein, I.D., Levitt, R.E., and Hayes-Roth, B. "Site-layout modeling: how can artificial intelligence help?" Journal of Construction Engineering and Management, ASCE, 118(3), 594-611, 1992.

[14] Tommelein, I.D., Levitt, R.E., and Hayes-Roth, B. "SightPlan model for site layout." Journal of Construction Engineering and Management, ASCE, 118(4), 749-766, 1992.

[15] Tommelein, I.D., and Zouein, P.P. "Interactive dynamic layout planning." Journal of Construction Engineering and Management, ASCE, 119(2), 266-287, 1993.

[16] Yeh, I-Cheng "Construction-site layout using annealed neural network." Journal of Computing in Civil Engineering, ASCE, 9(3), 201-207, 1995.

[17] Zouein, P.P. and Tommelein, I.D. "Dynamic layout planning using a hybrid incremental solution method." Journal of Construction Engineering and Management, ASCE, 125(6), 400-408, 1999. 